\title{
COUGH
}

\section{Abnormal oesophageal motility in patients with chronic cough}

\author{
J A Kastelik, A E Redington, I Aziz, G K Buckton, C M Smith, M Dakkak, A H Morice
}

Thorax 2003;58:699-702

See end of article for authors' affiliations ......................

Correspondence to: Professor A H Morice, Division of Academic Medicine, Castle Hill Hospital, Cottingham, East Yorkshire HU16 5JQ, UK; a.h.morice@hull.ac.uk

Revised version received 24 October 2002 Accepted for publication 23 April 2003
Background: Although gastro-oesophageal reflux is a recognised cause of chronic cough, the role of oesophageal dysmotility is unknown. The aim of this study was to determine the prevalence of abnormal oesophageal motility in a selected group of patients with chronic cough.

Methods: Oesophageal manometry and 24 hour $\mathrm{pH}$ monitoring were performed in 43 patients with chronic cough, 34 of whom had symptoms suggestive of gastro-oesophageal reflux. Comparative manometric measurements were made in 21 healthy subjects.

Results: Nine patients with chronic cough had normal manometry and 24 hour $\mathrm{pH}$. Of the remaining 34 patients, 11 (32\%) had abnormal manometry alone, five (15\%) had abnormal 24 hour pH monitoring alone, and in 18 (53\%) both tests were abnormal. Only one patient in the control group had manometric abnormalities.

Conclusions: These results point to a previously unrecognised high prevalence of abnormal oesophageal manometry in patients presenting with chronic cough. Oesophageal dysmotility may therefore be important in the pathogenesis of cough in these patients.
C hronic cough is a common and distressing symptom. ${ }^{1}$ In specialist cough clinics gastro-oesophageal reflux (GOR) is frequently found in association with chronic cough. ${ }^{2-15}$ GOR has generally been reported to account for $10-40 \%$ of cases, and it is recognised that cough may be the only presenting manifestation of otherwise asymptomatic GOR. ${ }^{16}$ On this basis, 24 hour ambulatory oesophageal $\mathrm{pH}$ monitoring has an established role in the diagnostic evaluation of patients with chronic cough.

Abnormal oesophageal motility is a rare finding in healthy subjects. ${ }^{17-19}$ In contrast, patients with peptic oesophagitis frequently have motility disorders including hypotensive lower oesophageal sphincter (LOS) and low amplitude or nontransmitted peristaltic waves. ${ }^{17}$ Previous uncontrolled studies of respiratory symptoms in patients with oesophageal dysmotility have suggested a possible association between abnormal manometry and chronic cough. ${ }^{20-23}$ However, oesophageal motility disorders have not been described as an associated finding or as a cause of cough in the reported experience of specialist cough clinics. ${ }^{2-15}$ A role for oesophageal manometry in the investigation of patients with chronic cough has therefore not been established.

The principal aim of this study was to examine the prevalence of oesophageal dysmotility in chronic cough and to determine the specific pattern of manometric abnormalities present. Oesophageal manometry was performed in a selected group of patients with chronic cough and comparative measurements were made in a control group of healthy subjects.

\section{METHODS \\ Subjects}

The study was performed in a specialist cough clinic at a university hospital. During the period from October 1998 to October 2000, 225 patients whose principal symptom was chronic cough, defined as a cough persisting for more than 8 weeks, were seen as new referrals. From this population we studied 34 patients (20 women) of mean age 57 years (range 37-72) and mean cough duration of 7.6 years (range $0.16-50$ ) who, at the initial assessment, reported symptoms suggestive of GOR such as heartburn, dysphagia, acid regurgitation, or an association between cough and posture or eating. These patients underwent oesophageal manometry and 24 hour pH monitoring on the basis of this clinical suspicion. Nine patients (three women) of mean age 58 years (range 30-76) and mean cough duration 13.5 years (range 1-41) in whom cough was an isolated symptom were also investigated. These patients underwent oesophageal manometry and 24 hour pH monitoring as the cause of cough was uncertain at the initial assessment. The control group consisted of 21 healthy volunteers of mean age 44 years (range 20-70) without any gastro-oesophageal or respiratory symptoms who underwent manometric studies. All subjects were non-smokers. Systemic disorders that might affect oesophageal motility were excluded clinically and no subject was receiving any form of medication that could alter upper gastrointestinal motor function.

The study was approved by the local research ethics committee and all subjects gave informed consent before investigative procedures.

\section{Oesophageal manometry}

Subjects attended the laboratory after a 4 hour fast. Oesophageal manometry was performed using a nine-lumen (eight channels plus central channel) radially orientated catheter (Mediplus; High Wycombe, Bucks, UK) perfused with water at a flow rate of $0.5 \mathrm{ml} / \mathrm{min} /$ channel using a low compliance pneumohydraulic capillary infusion system. The analogue transducer signal was captured on a digital recorder (Lectromed; Herts, UK) and manometric recordings were stored using specialised software. Airflow was measured using a thermistor positioned next to the nares, and any swallows were recorded with a miniature microphone securely taped over the throat. Manometry was performed using our previously described protocol. ${ }^{24}$ Briefly, the probe was passed transnasally into the stomach with the patient seated and the patient then moved to a supine position. To measure the LOS pressure the catheter was withdrawn from the stomach in $5 \mathrm{~mm}, 2.5 \mathrm{~mm}$, and $1.25 \mathrm{~mm}$ increments using a station pull through technique. Recordings were performed every five stable expiratory cycles to determine the maximal resting LOS pressure and to locate the proximal LOS border. The LOS was studied at the site of maximum end expiratory pressure (abdominal component); the respiratory inversion point 
Table 1 Numbers of patients with specific manometric abnormalities, and clinical response to antireflux treatment

\begin{tabular}{lll}
\hline Manometric abnormality & $\begin{array}{l}\text { Abnormal manometry and } \\
\text { abnormal pH monitoring }\end{array}$ & $\begin{array}{l}\text { Abnormal manometry } \\
\text { alone }\end{array}$ \\
\hline Low LOS pressure & $5(4)$ & $2(2)$ \\
Dysmotility & $5(3)$ & $1(1)$ \\
OMA & $3(3)$ & $2(0)$ \\
Low LOS pressure and dysmotility & $3(3)$ & $4(4)$ \\
Low LOS pressure and OMA & $2(2)$ & $2(2)$ \\
Total & $18(15)$ & $11(9)$ \\
\hline LOS=lower oesophageal sphincter; OMA=other manometric abnormalities. \\
Data are shown as total number of patients in each category with numbers responding to treatment in \\
parentheses.
\end{tabular}

where the end expiratory pressure changed from a negative to a positive deflection; and at the site of the maximum end expiratory pressure proximal to the respiratory inversion point (thoracic component). A series of wet swallows $(5 \mathrm{ml}$ water at $20-25^{\circ} \mathrm{C}$ ) performed at the site of maximum abdominal resting pressure was used to study LOS relaxation. If gastric contractions were observed, LOS pressure values were ignored during these periods.

Once the LOS pressures had been measured the catheter was reintroduced into the stomach and the withdrawal procedure repeated throughout the oesophageal body. The probe was positioned with the transducer $3,8,13,18$, and (if the oesophagus was of sufficient length) $23 \mathrm{~cm}$ above the proximal LOS border. Ten wet swallows were then given, each swallow separated by five inspiratory cycle intervals after the end of distal contraction. Whenever spontaneous swallowing, secondary contractions (propagated contractile activity initiated in the proximal oesophagus, not associated with swallowing), or tertiary contractions (non-propagated contractile activity occurring spontaneously within isolated segments of the oesophageal body) occurred during this sequence, a further $20 \mathrm{~s}$ interval was maintained until the next water swallow was administered. Motility analysis was performed on the basis of these 10 wet swallows.

For the purpose of the study manometric abnormalities were divided into three categories adapted from definitions proposed by Leite et al $^{25}$ :

(1) Oesophageal dysmotility was diagnosed when the number of non-transmitted contractions was $\geqslant 30 \%$ of the total number of swallows within the wet swallow series or when low amplitude peristaltic contractions were $<15 \mathrm{~cm} \mathrm{H}_{2} \mathrm{O}$.

(2) Low LOS pressure was defined as a pressure of $<10 \mathrm{~cm} \mathrm{H}_{2} \mathrm{O}$ (abdominal component).

(3) All other abnormal findings-including double peaked contractions, triple peaked contractions, simultaneous contractions, and tertiary contractions-were classified as other manometric abnormalities (OMA).

\section{4 hour ambulatory $\mathrm{pH}$ monitoring}

24 hour ambulatory $\mathrm{pH}$ monitoring was performed as previously described ${ }^{26}$ using a glass $\mathrm{pH}$ electrode (MettlerToledo Ltd; Leicester, UK) connected to a portable data storage unit (Digitrapper MKII Gold Medtronic; Synectics AB Medical; Stockholm, Sweden) equipped with an event marker to record cough. The electrode was calibrated at $\mathrm{pH} 7$ and $\mathrm{pH} \mathrm{l}$ before each study. The LOS was located manometrically as described above and the electrode was placed $5 \mathrm{~cm}$ above its proximal margin. Oesophageal $\mathrm{pH}$ was recorded every 4 seconds over a 24 hour period. Patients were encouraged to carry out normal daily activities but some dietary restrictions were imposed. After recording was completed, data were downloaded onto an IBM compatible computer and the percentage of total time with $\mathrm{pH}$ at $<4.0$ was calculated using appropriate software (Synectics AB Medical). pH monitoring findings were considered abnormal when a $\mathrm{pH}<4.0$ was recorded for $\geqslant 4.0 \%$ of the total 24 hour period. A reflux event was defined as a fall in $\mathrm{pH}$ to $\leqslant 4$ for $>12$ seconds. A cough event was considered temporally associated with reflux when a fall in $\mathrm{pH}$ to $\leqslant 4$ occurred simultaneously with cough or within the 5 minute period preceding the cough. ${ }^{27} 28$

\section{Therapeutic trial}

To address the possible clinical significance of our observations we assessed the response to antireflux therapy in patients with chronic cough, with and without abnormal manometry. Treatment included proton pump inhibitors (omeprazole $20-40 \mathrm{mg}$ daily or equivalent), alginates, and conventional advice regarding diet and posture. Response was assessed at a follow up visit after at least 3 months of treatment. Treatment was considered successful when the complaint of cough was no longer present or had markedly improved.

\section{Statistical analysis}

Data for age, cough duration, and LOS pressure were expressed as mean (range). Fisher's exact test was used to compare groups and to study the relationship between symptoms and abnormal investigations. Data were analysed using StatView 5.02 for Macintosh (Abacus Concepts, Berkeley, CA, USA). A p value of $<0.05$ was regarded as statistically significant.

\section{RESULTS}

\section{Prevalence of abnormal oesophageal 24 hour pH} monitoring and manometry

Nine of the 43 patients with chronic cough had normal oesophageal manometry and 24 hour $\mathrm{pH}$ monitoring. Of the remaining 34 patients, 11 (32\%) had abnormal manometry alone, five (15\%) had abnormal 24 hour pH monitoring alone, and in 18 cases $(53 \%)$ both tests were abnormal. Abnormal manometry, either alone or in association with abnormal 24 hour pH monitoring, was therefore recorded in $29(67 \%)$ patients. Conversely, abnormal 24 hour $\mathrm{pH}$ monitoring alone or in association with abnormal manometry was present in 23 (53\%) patients. A temporal association between cough and reflux events was present in $16(70 \%)$ patients with abnormal 24 hour $\mathrm{pH}$ monitoring and four (36\%) patients with abnormal manometry alone. The specific manometric abnormalities identified are detailed in table 1. Low LOS pressure was present in 18 cases and was the most common finding. In the control group one subject had oesophageal dysmotility, with $30 \%$ of contractions in the wet swallow series that were non-transmitted. All subjects in the control group had normal LOS pressures (mean 17.5 (range 11.6-22.3) $\mathrm{cm} \mathrm{H}_{2} \mathrm{O}$ ) and no control subject had OMA. The prevalence of abnormal manometry in this group was therefore $4.8 \%$ compared with $67.4 \%$ in the patients with chronic cough (size of effect $62.7 \%$ (95\% CI 46.0 to 79.4 ), $\mathrm{p}<0.0001$ ). 


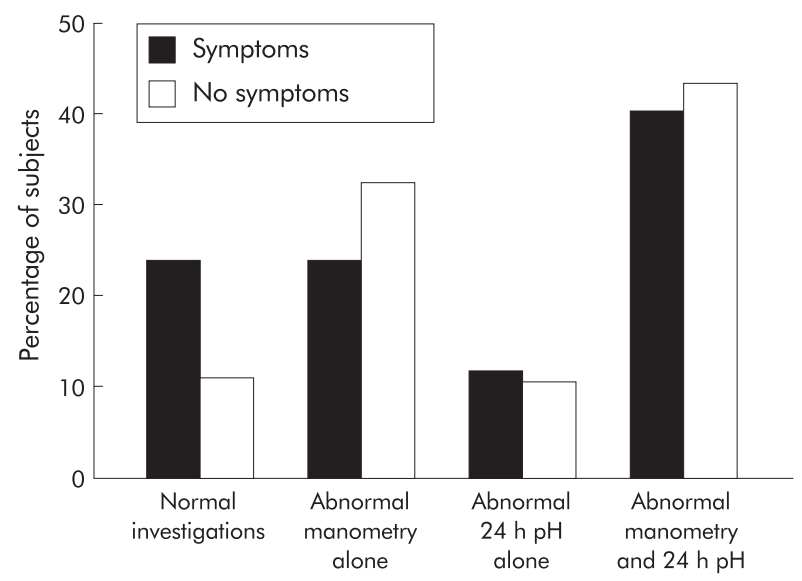

Figure 1 Results of oesophageal manometry and 24 hour ambulatory $\mathrm{pH}$ monitoring in patients with chronic cough with $(n=34)$ and without $(n=9)$ symptoms of gastro-oesophageal reflux.

\section{Relationship to gastro-oesophageal symptoms} Symptoms suggestive of GOR were reported by 34 patients. Eight $(24 \%)$ of these had normal investigations compared with only one $(11 \%)$ of the nine patients without gastrooesophageal symptoms. The proportions of patients with abnormal manometry, abnormal 24 hour pH monitoring, or both were similar in patients with and without symptoms (fig 1). There was no significant relationship between the presence of symptoms and the frequency of abnormal test results $(\mathrm{p}=0.66)$

\section{Response to antireflux therapy}

Of the 34 patients with at least one abnormal investigation, 28 $(82 \%)$ reported an improvement in the symptom of cough in response to antireflux therapy. The response rate was very similar in patients with abnormal $\mathrm{pH}$ tests alone $(80 \%)$, patients with abnormal manometry alone $(81 \%)$, and patients in whom both investigations were abnormal (83\%). Five of the eight patients with abnormal measurements but without gastro-oesophageal symptoms responded to antireflux therapy. A therapeutic trial of antireflux therapy was also performed in eight of the nine patients with normal results, the cough having resolved spontaneously in the remaining patient. None of the eight patients reported an improvement in the symptom of cough. Subsequent investigations showed that three of these had cough variant asthma and a further three had postnasal drip syndrome/rhinitis. In the other two cases the cause of cough was undetermined and the condition was therefore considered idiopathic.

\section{DISCUSSION}

The most important original finding of this study was the high prevalence of abnormal manometric measurements. Two thirds of the study population fulfilled our criteria for abnormal manometry, and in over a third of these patients this was the only positive finding. The prevalence of abnormal manometry was similar in patients with cough and associated gastro-oesophageal symptoms and in patients with isolated chronic cough. Abnormal oesophageal motility did not appear to be associated with the symptom of cough per se, however, as most of the patients with normal investigations were subsequently shown to have diagnoses other than GOR. In the control group, by contrast, only one of 21 subjects had abnormal manometric measurements. This is consistent with previous reports suggesting a low prevalence of oesophageal motility disorders in the general population. For example, only one of 31 normal volunteers and none of 48 patient controls studied by Kahrilas et $\mathrm{al}^{17}$ had abnormal peristalsis. None of these subjects had low LOS pressure. Richter $e t$ al ${ }^{18}$ found a similar low prevalence of abnormal manometric measurements in a study of 95 healthy volunteers.

In patients with chronic cough the prevalence of oesophageal dysmotility has previously received very little attention. Of almost 1500 patients investigated in specialist cough clinics, oesophageal motility disorders have not been described as either an association or a cause of cough in any of the 250 cases diagnosed with gastro-oesophageal disease..$^{2-15}$ Irwin et $a l^{26}$ and Brightling et $a l^{13}$ analysed motility in individual cases but provided no information regarding abnormal findings. In a retrospective analysis of all oesophageal studies performed over a 6 year period at a single centre, Fouad et al ${ }^{22}$ described manometric measurements in 43 patients with chronic cough and GOR defined by abnormal 24 hour pH monitoring. Ineffective oesophageal motility, broadly corresponding to our category of oesophageal dysmotility, was present in approximately half the patients. Low LOS pressure was an infrequent finding. This contrasts with our observation of a low LOS pressure as the single most common manometric abnormality in patients presenting with chronic cough. Knight et $a l^{23}$ reported that, among 112 patients referred for otorhinolaryngological assessment, 17 of 19 patients with laryngopharyngeal reflux and chronic cough had oesophageal motility disorders. Finally, Ours et $a l^{21}$ reported abnormal manometry in 10 of 23 subjects with chronic cough undergoing investigation for suspected GOR, including ineffective peristalsis/low amplitude contractions in four cases and low LOS pressure in two. However, the authors made no comment on the possible significance of these observations.

A number of studies, ${ }^{28-31}$ mostly uncontrolled, have reported that antireflux therapy improves chronic cough in patients with GOR demonstrated by 24 hour $\mathrm{pH}$ monitoring. Reported response rates have been in the range of $70-100 \%$, consistent with the present findings that $82 \%$ of such patients responded to treatment. In patients with abnormal manometry but normal 24 hour $\mathrm{pH}$ monitoring we found a similar response rate of $81 \%$. To our knowledge, an improvement in the symptom of cough with antireflux therapy has not previously been reported in this group of patients. Since the treatment trial was performed in an open manner, we cannot exclude a spontaneous resolution of cough or a placebo effect to explain our therapeutic success. However, a previous controlled study of antireflux therapy in patients with chronic cough did not suggest a marked placebo response. ${ }^{31}$ Furthermore, the prolonged history of cough before treatment and the lack of response to treatment in patients with normal investigations both argue against spontaneous resolution or placebo effect.

The mechanism of cough associated with GOR has been investigated by direct instillation of acid into the lower oesophagus. Ing et al ${ }^{32}$ demonstrated a median response of 36 coughs to an infusion of $0.1 \mathrm{M} \mathrm{HCl}$ in patients with GOR and chronic cough compared with only occasional coughs in normal subjects. In these same patients over half coughed with intra-oesophageal $0.9 \%$ saline infusion. Irwin et $a l^{28}$ also observed that infusion of $0.9 \%$ saline into the lower oesophagus induced cough in a quarter of patients with GOR related cough. These findings indicate that receptors capable of precipitating cough are undoubtedly present in the oesophagus, and that low intraluminal pH may not be the only stimulus.

How might the manometric abnormalities demonstrated in our study lead to cough? Low LOS pressure could cause volume reflux resulting in mechanical stimulation of oesophageal cough receptors, consistent with the observation that oesophageal saline infusion causes cough. ${ }^{28}{ }^{32}$ Low LOS pressure may also result in non-acid reflux which is detectable by intra-oesophageal impedance measurement ${ }^{33}{ }^{34}$ but not by conventional 24 hour $\mathrm{pH}$ monitoring. Alternatively, the heightened cough reflex described in patients with chronic cough $^{7}$ may trigger episodes of cough at a degree of acid reflux 
that does not fulfil the definition of GOR. This may explain the response to antireflux therapy in patients with a "normal" $\mathrm{pH}$ profile in this report and in other studies. ${ }^{28}$ Disordered peristalsis may lead to impaired oesophageal clearance, as has been reported in a proportion of patients with chronic cough. ${ }^{35}$ This could result in prolonged stimulation of oesophageal cough receptors or microaspiration of oesophageal contents ${ }^{36}$ causing direct stimulation of laryngeal and tracheal cough receptors. Finally, oesophageal receptors might be activated by intramural tension in the context of oesophageal dysmotility.

In conclusion, our findings point to a previously unrecognised high prevalence of oesophageal manometric abnormalities in patients presenting with chronic cough, irrespective of the presence of gastro-oesophageal symptoms. Abnormal oesophageal motility may therefore be important in the pathogenesis of cough in these patients. Normal 24 hour $\mathrm{pH}$ monitoring does not exclude the oesophagus as a source of cough and does not rule out a response to antireflux therapy. We suggest that oesophageal manometry should be considered in patients with unexplained chronic cough.

\section{Authors' affiliations}

J A Kastelik, A E Redington, I Aziz, A H Morice, Division of Academic Medicine, Postgraduate Medical Institute, University of Hull, Hull, UK G K Buckton, C M Smith, M Dakkak, Department of Gastroenterology, Hull Royal Infirmary, Hull, UK

\section{REFERENCES}

1 French CL, Irwin RS, Curley FJ, et al. Impact of chronic cough on quality of life. Arch Intern Med 1998;158:1657-61.

2 Irwin RS Corrao WM, Pratter MR. Chronic persistent cough in the adult: the spectrum and frequency of causes and successful outcome of specific therapy. Am Rev Respir Dis 1981;123:413-7.

3 Poe RH, Israel RH, Utell M, et al. Chronic cough: bronchoscopy or pulmonary function testing? Am Rev Respir Dis 1982;126:160-2.

4 Poe RH, Harder RV, Israel RH, et al. Chronic persistent cough: experience in diagnosis and outcome using an anatomic diagnostic protocol. Chest 1989;95:723-8.

5 Puolijoki H, Lahdensuo A. Causes of prolonged cough in patients referred to a chest clinic. Ann Med 1989;21:425-7.

6 Irwin RS, Curley FJ, French CL. Chronic cough: the spectrum and frequency of causes, key components of the diagnostic evaluation, and outcome of specific therapy. Am Rev Respir Dis 1990;141:640-7.

7 O'Connell F, Thomas VE, Pride NB, et al. Capsaicin cough sensitivity decreases with successful treatment of chronic cough. Am J Respir Crit Care Med 1994;150:374-80.

8 Hoffstein V. Persistent cough in nonsmokers. Can Respir J 1994;1:40-7.

9 Smyrnios NA, Irwin RS, Curley FJ. Chronic cough with a history of excessive sputum production: the spectrum and frequency of causes, key components of the diagnostic evaluation, and outcome of specific therapy. Chest 1995;108:991-7.

10 Mello CJ, Irwin RS, Curley FJ. Predictive values of the character, timing, and complications of chronic cough in diagnosing its cause. Arch Intern Med 1996;156:997-1003

11 Marchesani F, Cecarini L, Pela R, et al. Causes of chronic persistent cough in adult patients: the results of a systematic management protocol. Monaldi Arch Chest Dis 1998;53:510-4.

12 McGarvey LPA, Heaney LG, Lawson JT, et al. Evaluation and outcome of patients with chronic non-productive cough using a comprehensive diagnostic protocol. Thorax 1998;53:738-43.
13 Brightling CE, Ward R, Goh KL, et al. Eosinophilic bronchitis is an important cause of chronic cough. Am J Respir Crit Care Med 1999; 160:406-10

14 Palombini BC, Villanova CA, Araújo $\mathrm{E}$, et al. A pathogenic triad in chronic cough: asthma, postnasal drip syndrome, and gastroesophageal reflux disease. Chest 1999;1 16:279-84.

15 Simpson G. Investigation and management of persistent dry cough. Thorax 1999:54:469

16 Irwin RS, Zawacki JK, Curley FJ, et al. Chronic cough as the sole presenting manifestation of gastroesophageal reflux. Am Rev Respir Dis 1989; 140: 1294-1300.

17 Kahrilas PJ, Dodds WJ, Hogan WJ, et al. Esophageal peristaltic dysfunction in peptic esophagitis. Gastroenterology 1986:91:897-904.

18 Richter JE, Wu WC, Johns DN, et al. Esophageal manometry in 95 healthy adult volunteers: variability of pressures with age and frequency of "abnormal" contractions. Dig Dis Sci 1987;32:583-92.

19 Kahrilas PJ, Clouse RE, Hogan WJ. American Gastroenterological Association technical review on the clinical use of esophageal manometry. Gastroenterology 1994; 107: 1865-84.

20 DeMeester TR, Bonavina L, lascone C, et al. Chronic respiratory symptoms and occult gastroesophageal reflux: a prospective clinical study and results of surgical therapy. Ann Surg 1990;211:337-45.

21 Ours TM, Kavuru MS, Schilz RJ, et al. A prospective evaluation of esophageal testing and a double-blind, randomized study of omeprazole in a diagnostic and therapeutic algorithm for chronic cough. Am J Gastroenterol 1999:94:3131-8.

22 Fouad YM, Katz PO, Hatlebakk JG, et al. Ineffective esophageal motility: the most common motility abnormality in patients with GERD-associated respiratory symptoms. Am J Gastroenterol 1999;94:1464-7.

23 Knight RE, Wells JR, Parrish RS. Esophageal dysmotility as an important co-factor in extraesophageal manifestations of gastroesophageal reflux. Laryngoscope 2000;110:1462-6.

24 Evans DF, Buckton GK. Static Manometry. In: Evans DF, Buckton GK, eds. Clinical measurements in gastroenterology. Volume 1/The oesophagus. Blackwell Science, 1997: 16-79.

25 Leite LP, Johnston BT, Barrett J, et al. Ineffective esophageal motility (IEM): the primary finding in patients with nonspecific esophageal motility disorder. Dig Dis Sci 1997;42:1859-65.

26 Pryde A. Procedures for prolonged pH monitoring. In: Evans DF, Buckton GK, eds. Clinical measurement in gastroenterology. Volume 1/The oesophagus. Oxford: Blackwell Science, 1997: 100-11.

27 Ing AJ, Ngu MC, Breslin ABX. Chronic persistent cough and gastro-oesophageal reflux. Thorax 1991;46:479-83.

28 Irwin RS, French CL, Curley FJ, et al. Chronic cough due to gastroesophageal reflux: clinical, diagnostic, and pathogenetic aspects. Chest 1993; 104:1511-7

29 FitzGerald JM, Allen CJ, Craven MA, et al. Chronic cough and gastroesophageal reflux. Can Med Assoc J 1989;140:520-4.

30 Waring JP, Lacayo L, Hunter J, et al. Chronic cough and hoarseness in patients with severe gastroesophageal reflux disease: diagnosis and response to therapy. Dig Dis Sci 1995;40:1093-7.

31 Kijander TO, Salomaa ERM, Hietanen EK, et al. Chronic cough and gastro-oesophageal reflux: double-blind placebo-controlled study with omeprazole. Eur Respir J 2000;16:633-8.

32 Ing AJ, Ngu MC, Breslin ABX. Pathogenesis of chronic persistent cough associated with gastroesophageal reflux. Am J Respir Crit Care Med 1994; 149:160-7.

33 Sifrim D, Holloway R, Silny J, et al. Acid, nonacid, and gas reflux in patients with gastroesophageal reflux disease during ambulatory 24-hour pH-impedance recordings. Gastroenterology 2001;120:1588-98.

34 Vela MF, Camacho-Lobato L, Srinivasan R, et al. Simultaneous intraesophageal impedance and $\mathrm{pH}$ measurement of acid and nonacid gastroesophageal reflux: effect of omeprazole. Gastroenterology 2001;120:1599-606

35 Ing AJ, Ngu MC, Breslin ABX. Chronic persistent cough and clearance of esophageal acid. Chest 1992;102:1668-71.

36 Patti MG, Debas HT, Pellegrini CA. Esophageal manometry and 24-hour $\mathrm{pH}$ monitoring in the diagnosis of pulmonary aspiration secondary to gastroesophageal reflux. Am J Surg 1992;163:401-6. 